\title{
A study of expertise effects for products with contradictory semantics
}

\author{
Ching-Yi Wang ${ }^{a}$ \\ Department of Industrial Design, Tatung University, Taipei City 104, Taiwan
}

\begin{abstract}
In the design studies, researchers often use the semantic differential method with bipolar adjectives, such as "modern vs. classical" or "simple vs. complex" when investigating the semantics projected by product forms. However, in design practice, some design examples clearly exhibit the simultaneous use of contradictory meanings in product semantics. For example, retro car evokes nostalgia by borrowing characteristics from classical cars. At the same time it exhibits a modern style. However, most studies measure the product semantics mostly by using subjective measurement. There is lack objective measurement for that. In this research, we examined the results of applying the semantic differential method to measure contradiction in product semantics. The results showed that the distributions of semantic differential ratings for the stimuli with contradictory meanings have higher standard deviations. The sensitivity of semantic recognition may depend on participant expertise. The design experts are trained to be good at visual thinking that could easily identify the contradiction semantics between products. In general, successful embedding of contradictory meanings into product forms are based on simple, typical, and rational forms that can display complex, novel, and perceptual images by adding supplementary elements.
\end{abstract}

\section{Introduction}

Nowadays, the rapid developments in art and design have created an almost limitless number of items in the same category (for example, chairs in the category of furniture) that have a variety of features and different design styles. Scenes of conflicting furniture arrangement in a space are commonplace, for example, a modern floor lamp next to a classic sofa. How do people react to the scenes of contradiction? In design studies, the most popular method of measuring participants' reactions to objects or images is to apply adjectival descriptions of the semantic differences (STD) and to employ a multidimensional scale (MDS). The studies use questionnaires with a Likert scale, mostly based on the semantics analysis developed by Osgood in 1957 to acquire the participant's subjective responses to stimuli [1]. Different bipolar adjectives (e.g., simple-complicated, plain-luxurious) are tested according to the stimuli and context, in the semantic differential measurement. However, these types of surveys were subjective measurements. Many results have been realized [2-4], and the criticism regarding this method of measurement has arisen for several reasons: (1) that the participants' response may be misguided due to the questionnaire design (2) insufficient reliability and accuracy (3) participants will not answer all of the questions with sufficient care. As the process of acquiring the

\footnotetext{
${ }^{\mathrm{a}}$ Corresponding author : catincar@gmail.com
} 
raw data is not well controlled, the subsequent data analysis may be invalid. In addition, there are many products with both typical and unique visual appearance, such as the "ice lamp" (see Figure 1) which was covered with transparent glass displays warm and cold at the same time. In response to a product within a double semantics, participants generally check a middle option with the hesitant and uncertain attitude (i.e. neutral response) using 7-point bipolar adjective scale. It is difficult to identify their true feelings. In addition, this answer is often considered invalid questionnaires.
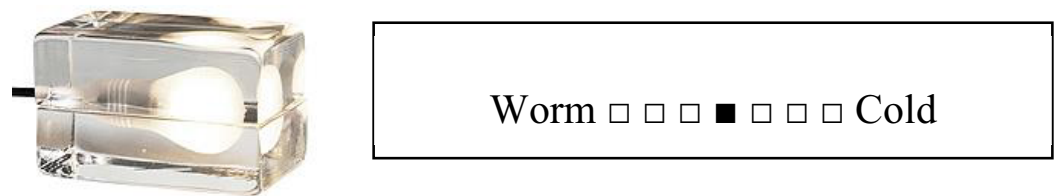

Figure 1. The "ice lamp" product displays a double semantics within warm and cold.

The terms of ambivalence or conjunctive ambiguity are similar with semantic contradiction. The definition of ambivalence includes "a state of mind" when people feel mixed feelings (usually a positive or negative sense) to an object [5]. It can also be seen as "conflict feeling" which aroused by many competitions and assessments of the propositions [6]. It was summarized as "circumplex model" which may explain basic human emotions by two orthogonal dimensions representing "pleasantness" (horizontal, from negative, painful dark to positive, bright) and "activation" (vertical, from introvert to extrovert) [6-9].

Regarding the contradictory semantic study, the method of standard deviation was used to select products which may involve the conflict semantics [2]. They believe that the semantic contradiction would be affected by three factors comprising at odds, contradiction, and insensitivity. They assumed that the measurement results of contradictory semantics may be presented by three types of modes as shown in the Figure 2. Figure 2(a) appears two peaks if participants clearly and respectively perceive the differences across the two semantics. Figure 2(b) shows three peaks if the participants perceive the double semantics because they are unsure about choosing answer. Figure 2(c) displays almost flat distribution if the participants perceive uncertain or unstable semantics due to random guessing. In the preceding three assumptions, they should be appeared a large standard deviation (Std), negative kurtosis $(\mathrm{K})$ value, and the average value (mean) near central (skewness $(\mathrm{S})=0$ ).

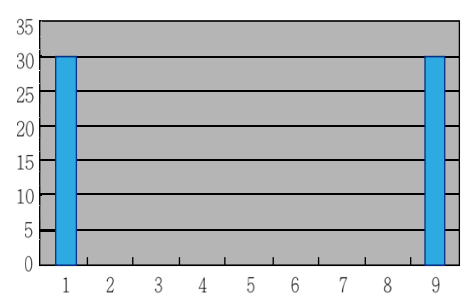

(a) two peaks

Mean=5; $\mathrm{Std}=4.034$

$\mathrm{S}=0 ; \mathrm{K}=-2.07$

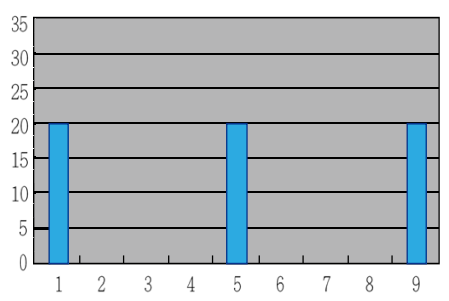

(b) three peaks

Mean=5; Std=3.294

$\mathrm{S}=0 ; \mathrm{K}=-1.526$

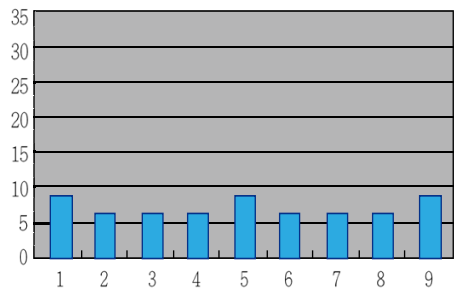

(c) random guessing

Mean=5; Std=2.681

$\mathrm{S}=0 ; \mathrm{K}=-1.243$

Figure 2. Examples of three conditions of conflict semantic distribution [2].

In the present study, the chair products were as sample to classify using the card sorting. The analysis method using [2] recommended as an indicator to select and define the pictures with and without contradictory semantics. Four dimensions of semantics were used according to the previous studies [11-12], including novel (typical - unique), modern dimension (traditional - modern), perceptual (rational - emotional), and complicated (complicated - simple). We expect to get a reasonable explanation corresponding to contradiction semantics and strengthen this topic for understanding clearly.

\section{Methods}




\subsection{Participants}

Sixty participants comprised of 30 experts $(11$ male, 9 female; mean age $=23.6$ years $)$ with design training background and 30 novices ( 9 male, 11 female; mean age $=28.6$ years, $\mathrm{STD}=13.65$ years) without design training background in the experiment. Different background was used to understand their cognitive differences in response to product works with contradiction semantics.

\subsection{Materials}

The stimuli included 396 colour pictures of chairs without armrest component (see Figure 3) on a white background. All of the selected pictures acquired via the book 1000 Chairs [12], 500 Chairs [13], and the works by famous designers from Internet. The reason for choosing the chair is that they have various styles and represent one of the most famous products in the design history. These pictures were displayed at a subtended vertical and horizontal visual angle of approximately 45 degrees for better viewing. Each picture was approximately $10 \mathrm{~cm}$ high and $10 \mathrm{~cm}$ wide and marked a corresponding number at the bottom of the right.

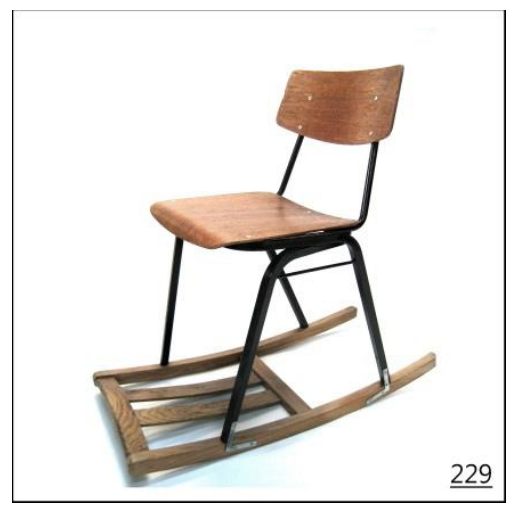

Figure 3. Example picture.

\subsection{Procedure}

There are two stages in the image clustering, as shown in the Figure 4. In the first stage, the categorization was performed by 6 design experts. The remaining 96 chairs were divided into 4 groups of 24 chairs each. Each dimensions corresponded to one of the following 4 semantics: novel (typical unique), modern dimension (traditional - modern), perceptual (rational - emotional), and complicated (complicated - simple) [11-12].

In the second stage, each dimension with respect to one of the pairs of adjectives was divided into 9 subgroups corresponding to a 9-point rating scale, as shown in the Table 1 . In order to reduce the participants' cognitive loading, each dimension was first divided into 3 groups, representing low, middle and high levels, and then to further divides each of these groups into 3 subgroups, thus arriving at a total of 9 groups. The number of each group was allowed to be uneven or void. After finish card sorting, each participant was asked questions regarding the classified reasons for each group. The overall test took 90 minutes to complete. 

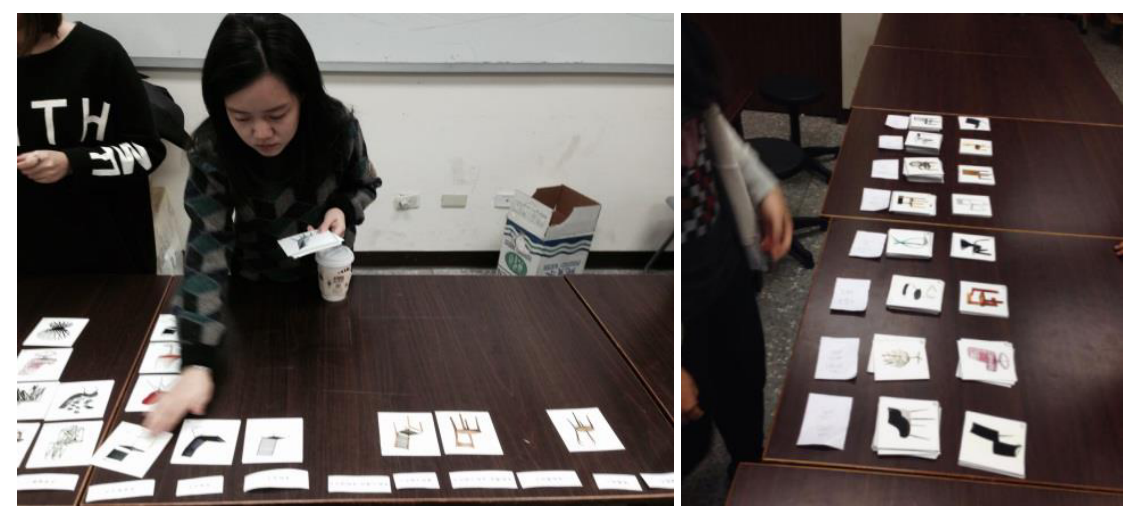

Figure 4. Card sorting: each semantic dimension with respect to one of the pairs of adjectives was divided into 9 subgroups corresponding to a 9-point rating scale

Table 1. The 4 semantic dimensions of 3 groups which represented low, middle and high levels of 9 subgroups.

\begin{tabular}{|c|c|c|c|c|c|}
\hline $\begin{array}{l}\text { semantic } \\
\text { level }\end{array}$ & scale & novel & modern & perceptual & complicated \\
\hline \multirow{3}{*}{ low level } & 1 & highly typical & highly traditional & highly rational & highly complicated \\
\hline & 2 & very typical & very traditional & very rational & very complicated \\
\hline & 3 & a little typical & a little traditional & a little rational & a little complicated \\
\hline \multirow{3}{*}{ middle level } & 4 & $\begin{array}{l}\text { a little typical and } \\
\text { not unique }\end{array}$ & $\begin{array}{l}\text { a little traditional } \\
\text { and not modern }\end{array}$ & $\begin{array}{l}\text { a little rational and } \\
\text { not emotional }\end{array}$ & $\begin{array}{l}\text { a little complicated } \\
\text { and not simple }\end{array}$ \\
\hline & 5 & $\begin{array}{l}\text { both typical and } \\
\text { unique }\end{array}$ & $\begin{array}{l}\text { Both traditional } \\
\text { and modern }\end{array}$ & $\begin{array}{l}\text { both rational and } \\
\text { emotional }\end{array}$ & $\begin{array}{l}\text { both complicated } \\
\text { and simple }\end{array}$ \\
\hline & 6 & $\begin{array}{l}\text { not typical and a } \\
\text { little unique }\end{array}$ & $\begin{array}{l}\text { not traditional and } \\
\text { a little modern }\end{array}$ & $\begin{array}{l}\text { not rational and a } \\
\text { little emotional }\end{array}$ & $\begin{array}{l}\text { not complicated } \\
\text { and a little simple }\end{array}$ \\
\hline \multirow{3}{*}{ high level } & 7 & a little unique & a little modern & a little emotional & a little simple \\
\hline & 8 & very unique & very modern & very emotional & very simple \\
\hline & 9 & highly unique & highly modern & highly emotional & highly simple \\
\hline
\end{tabular}

\subsection{Data analysis}

Table 2. The representative samples in accordance with different level of semantics.

\begin{tabular}{|l|c|c|c|}
\hline $\begin{array}{r}\text { semantic level } \\
\text { analysis items }\end{array}$ & $\begin{array}{c}\text { low level } \\
\text { (range from 1 to 3) }\end{array}$ & $\begin{array}{c}\text { middle level } \\
\text { (range from 4 to 6) }\end{array}$ & $\begin{array}{c}\text { high level } \\
\text { (range from 7 to 9) }\end{array}$ \\
\hline mean $(\mathrm{M})$ & $1-3$ & $4-6$ & $7-9$ \\
\hline standard deviation (Std) & small & large & small \\
\hline skewness (S) & positive & negative & negative \\
\hline kurtosis (K) & positive & negative & positive \\
\hline
\end{tabular}

The descriptive statistics were first performed to identify a representative sample of 4 semantic dimensions. Table 2 shows the definitions of mean (M), standard deviation (Std), skewness (S), and kurtosis $(\mathrm{K})$ for each level of semantic. The independent-samples $\mathrm{T}$ test was performed to analyse the rating scores between different backgrounds which as death with independent variables. 


\section{Results}

\subsection{Overall means of four semantic dimensions}

Table 3-6 display the card sorting results of chair pictures with the perceptual, novel, modern, and complicated semantics. The middle column exhibits the contradictory semantic with the large standard deviation, and the left and right columns both present the high-level perceptions with small standard deviation to the corresponding to the bipolar adjective pairs.

\subsubsection{Perceptual products}

Table 3 shows the measurement results of chair with perceptual semantic. The chair (Table 5(a)) were rated the most rational because the seat and back were constructed by vertical and horizontal surfaces and displays rigid outline. Moreover, many participants considered that the chair (Table 5(b)) with large surface-seat and cylindrical metal legs displays soft and rigid combinations, respectively. In addition, the appearance of the chair (Table 5(c)) looks like a female body, such as its headrest, back, and legs respectively symbolize female's head, chest, and legs. Thus, it was rated the most sensual chair.

Table 3. Perceptual dimension (rational-emotional).

\begin{tabular}{|c|c|c|c|}
\hline & $\begin{array}{c}\text { highly rational } \\
\text { (small standard deviations) }\end{array}$ & $\begin{array}{c}\text { both rational and emotional } \\
\text { (large standard deviation) }\end{array}$ & $\begin{array}{c}\text { highly emotional } \\
\text { (small standard deviations) }\end{array}$ \\
\cline { 2 - 4 } & & & \\
& & &
\end{tabular}

Note: $\mathrm{M}=$ mean; $\mathrm{Std}=$ standard deviation; $\mathrm{S}=$ skewness; $\mathrm{K}=$ kurtosis.

\subsubsection{Novel products}

Table 4 shows the measurement results of chair with novel semantic. The wooden chair (Table 3(a)) was rated the most typical. This typical style of chair in the appearance and construction should be structured by a palisading seat/back and four-legged features. Moreover, a typical chair (Table 3(b)) added a back part which comes from another chair as a specially rocking function and made it displays a typical and unique combination. In addition, the unique chair (Table 3(c)) was completely made by a bathtub as its sitting function and confusing participants with its product category, thus they think that it is not a chair. 
Table 4. Novel dimension (typical-unique).

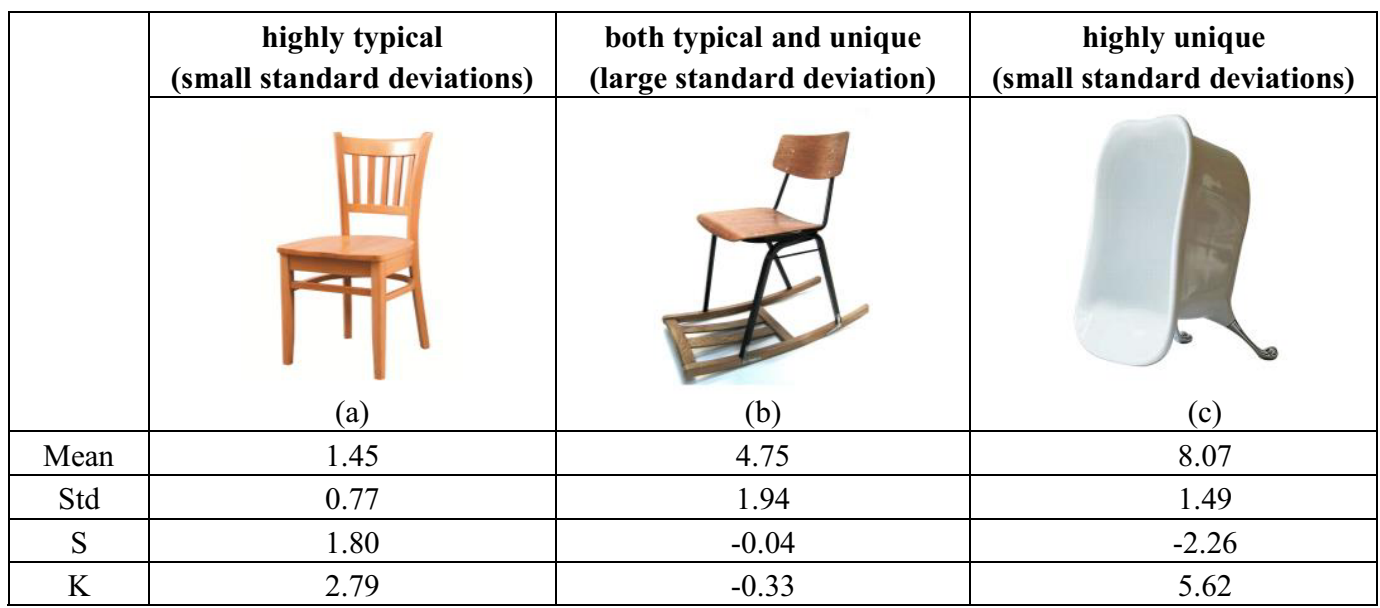

Note: $\mathrm{M}=$ mean; $\mathrm{Std}=$ standard deviation; $\mathrm{S}=$ skewness; $\mathrm{K}=$ kurtosis.

\subsubsection{Modern products}

Table 5 shows the measurement results of chair with modern semantic. The chair (Table 4a) was waved by bamboo and rattan and obviously looks an age-old style. Moreover, the chair which combined with traditional and modern style (Table $4 \mathrm{~b}$ ) has a traditional fencing structure of the seat with the technical metal legs. In addition, the metal chair (Table 4c) was made by an interwoven of bending and netted structure as a main body for supporting sitting function. Most participants believed that it should belong to the highly modern style.

Table 5. Modern dimension (traditional - modern).

\begin{tabular}{|c|c|c|c|}
\hline \multirow{1}{*}{} & $\begin{array}{c}\text { highly traditional } \\
\text { (small standard deviations) }\end{array}$ & $\begin{array}{c}\text { both traditional and modern } \\
\text { (large standard deviation) }\end{array}$ & $\begin{array}{c}\text { highly modern } \\
\text { (small standard deviations) }\end{array}$ \\
\cline { 2 - 4 } & & & \\
& & &
\end{tabular}

Note: $\mathrm{M}=$ mean; $\mathrm{Std}=$ standard deviation; $\mathrm{S}=$ skewness; $\mathrm{K}=$ kurtosis.

\subsubsection{Complicated products}

Table 6 shows the measurement results of chair with complicated semantic. The chair (Table 6a) was almost covered with colourful patches of hexagonal cloth, thus it was rated the most complex type by most participants. Moreover, the structure of chair (Table 6(b)) for its leg was composed by the simple and straight metal lines, but its back was complex. In addition, the chair (Table 5(c)) in the appearance 
has slender legs, hollow back, and thin seat, overall showing a minimalist form. Its appearance therefore easily seems as a simple type.

Table 6. Complicated dimension (complex-simple).

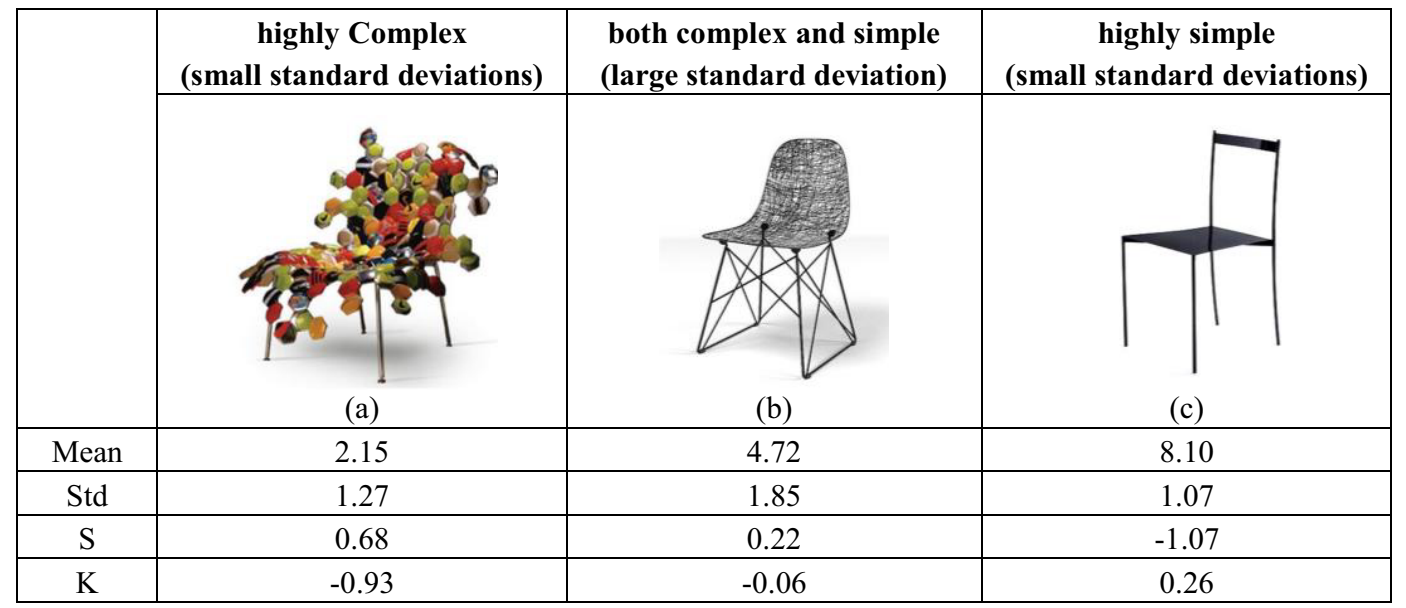

Note: $\mathrm{M}=$ mean; $\mathrm{Std}=$ standard deviation; $\mathrm{S}=$ skewness; $\mathrm{K}=$ kurtosis.

\subsection{Comparison of cognitive differences between experts and novices in response to the contradictory products}

In order to understand the different cognitive models between different backgrounds, we further preformed the T-test to examine the novel, modern, perceptual and complicated dimensions with the contradictory semantic products. According to the T-test analysis results, we found the conditions with significant differences for the contradictory chairs and use the frequency distribution figures to compare the cognitive differences between (average range from 4 to 6 scores) experts and novices, as shown in the Table 7-10.

\subsubsection{Perceptual products with contradictory semantics}

Table 7 shows the measurement results of perceptual chairs with contradictory semantics. The metal chair (Table 7(a)) was composed of many bending surfaces and three legs. The frequency distribution for the experts concentrated on the left (an average of 3 ), showing that they consistently agreed that it is the most rational chair. Nevertheless, the frequency distribution for novices presented double peaks, showing that a part of the participants considered that it is emotional style or not. There exist divergent views on this chair between novices.

Moreover, the shape of the chair is similar to the previous one (Table 7(b)), but it is a four-legged chair. The frequency distribution for the experts concentrated on the left (an average of 3.83), presenting that it is more rational. However, the frequency distribution for novices presented double peaks. Because some participants thought that its back legs are slanted and exhibits softness and tenderness.

In addition, the chair was composed by wooden and having high back structure (Table 7(c)). The frequency distribution for the experts focused on the middle, showing that it is a rational and emotional combination. Nevertheless, the frequency distribution for the experts concentrated on the right trend, showing that most novices believed the side contour for this chair presented S curve as a female body. 
Table 7. Perceptual chairs with contradictory semantics.

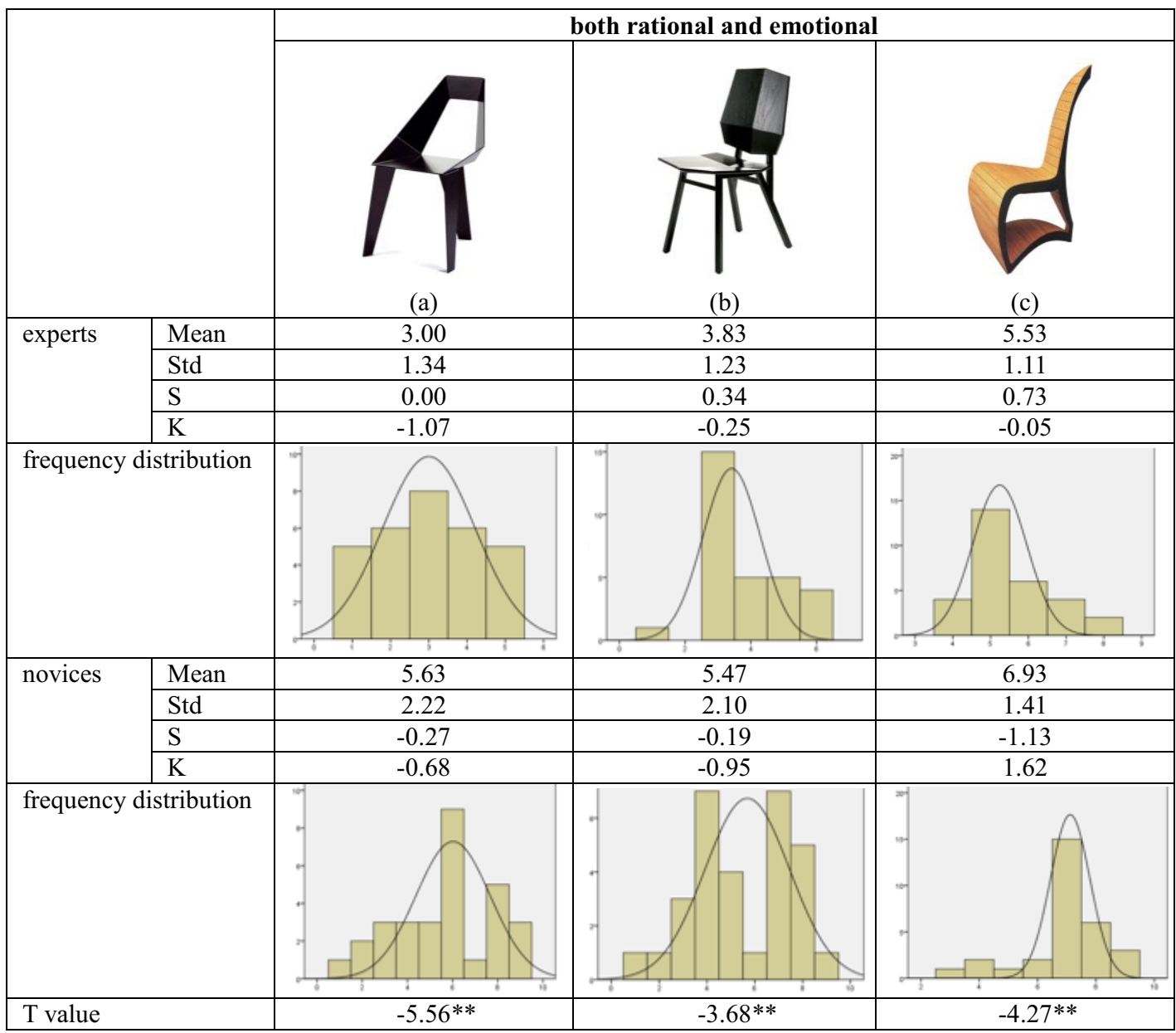

Note: $\mathrm{M}=$ mean; $\mathrm{Std}=$ standard deviation; $\mathrm{S}=$ skewness; $\mathrm{K}=$ kurtosis.

${ }^{*} \mathrm{p}<.05$ and ${ }^{* *} \mathrm{p}<.01$ (2-tailed)

\subsubsection{Novel products with contradictory semantics}

Table 8 shows the measurement results of novel chairs with contradictory semantics. The structure of this chair (Table 8(a)) was normal, but its seat was composed by hangers. Thus, the frequency distribution for the experts concentrated on the middle, showing it is conflict between typical and unique. Spuriously, most novices had not found its different part. The frequency distribution for novices concentrated on the left, showing that they thought it just a normal chair.

In addition, the chair's leg (Table 8(b)) was an upside down of back which comes from another chair. The frequency distribution for the experts focused on the middle, showing that it is also a conflicting type. However, the frequency distribution for the novices presented double peaks, showing that some participants considered that this chair belongs to typical or unique type.

The chair (Table 8(c)) obviously was two plastic chairs overlapping into one. Therefore, the frequency distribution for the experts focused on the middle, showing that they consistently agreed that this chair is conflict between typical and unique. Nevertheless, the frequency distribution for the novices displayed three peaks, showing that there are strong cognition differences between them. 
Table 8. Novel chairs with contradictory semantics.

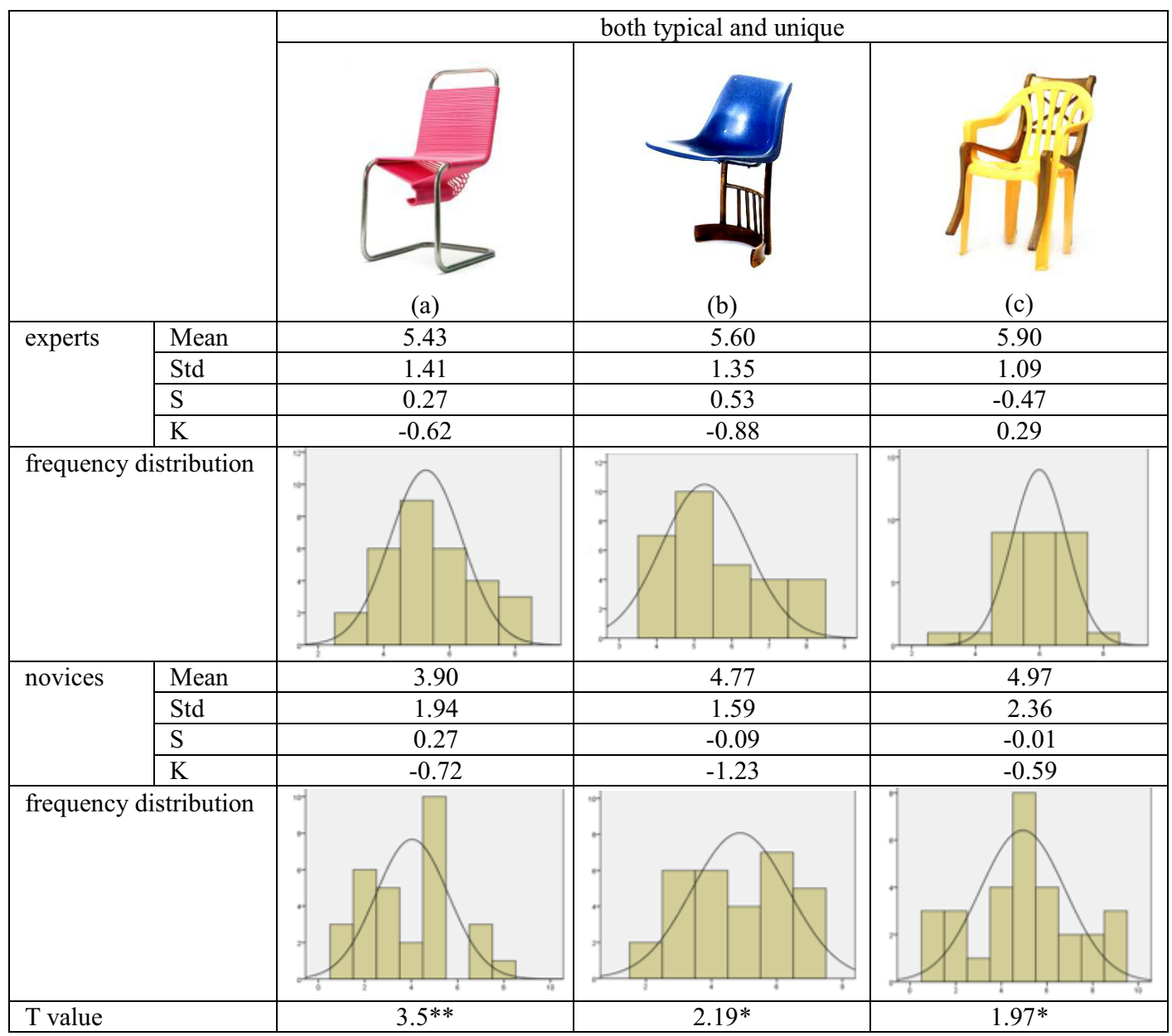

Note: $\mathrm{M}=$ mean; $\mathrm{Std}=$ standard deviation; $\mathrm{S}=$ skewness; $\mathrm{K}=$ kurtosis.

${ }^{*} \mathrm{p}<.05$ and ${ }^{* *} \mathrm{p}<.01$ (2-tailed)

\subsubsection{Modern products with contradictory semantics}

Table 9 shows the measurement results of modern chairs with contradictory semantics. The chair (Table 9a) was composed with wooden legs and cushion. The frequency distribution for the experts trended to the left (an average of 4.97), showing that this chair was more modern because its white cushion and simple back. However, the frequency distribution for the novices displayed a slightly trended to the right, showing that few novices considered that it still belongs to traditional because it's wooden and four-legged features.

Furthermore, the chair (Table 9b) in the appearance was not different from the classical type, but it is whole made of metal. The frequency distribution for experts presented double peaks. They really read its design history and even know the related design concept from original designer, considering that it is a newly re-designed product that reaches across past and current. They therefore hesitated to choose between tradition and modern. On the contrary, the novices without the design knowledge and product training. Their frequency distribution for the experts concentrated on the left (an average of 3), showing that this chair was undoubtedly considered a traditional type. 
Table 9. Modern chairs with contradictory semantics.

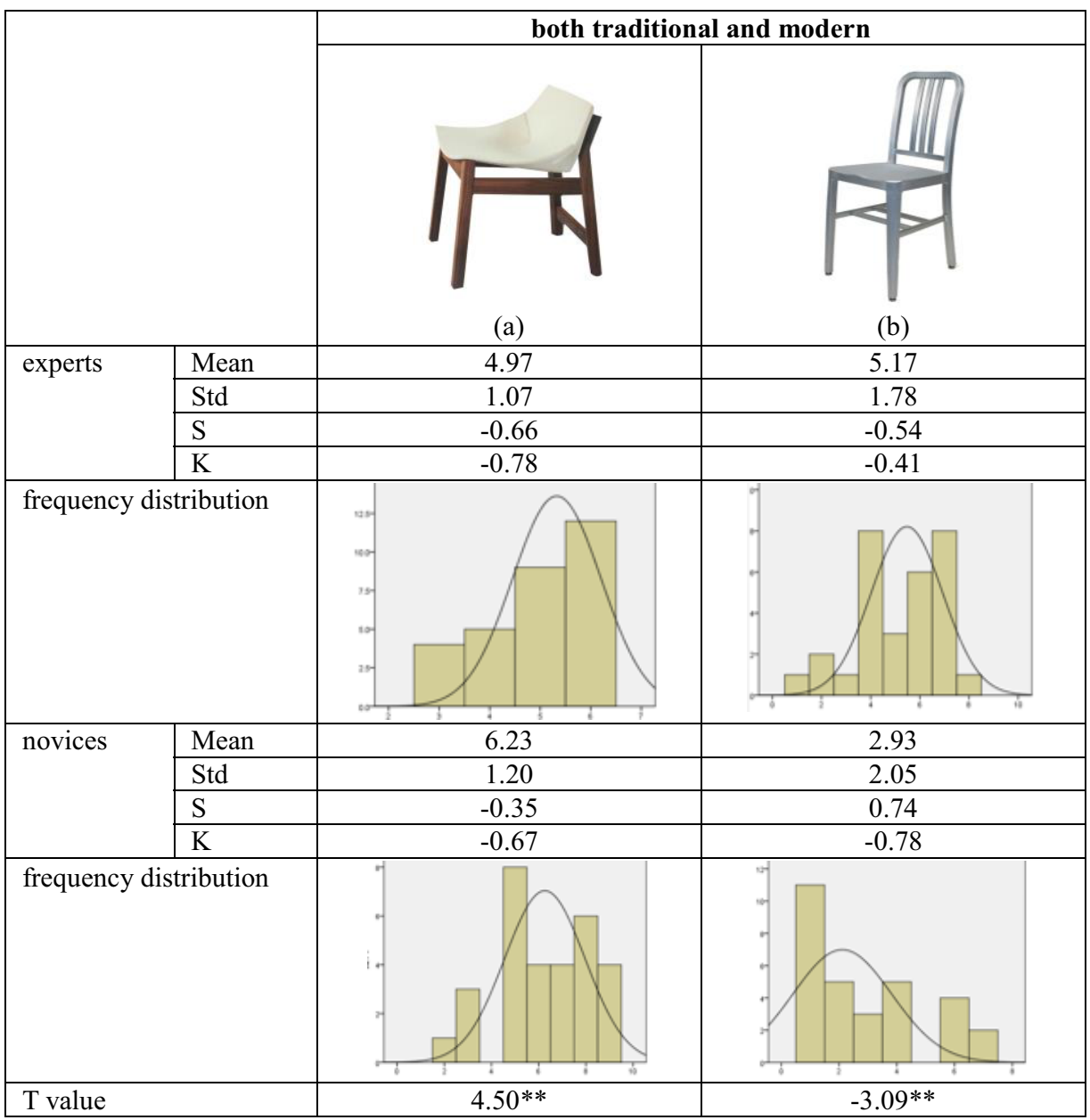

Note: $\mathrm{M}=$ mean; $\mathrm{Std}=$ standard deviation; $\mathrm{S}=$ skewness; $\mathrm{K}=$ kurtosis.

${ }^{*} \mathrm{p}<.05$ and ${ }^{* *} \mathrm{p}<.01$ (2-tailed)

\subsubsection{Complicated products with contradictory semantics}

Table 10 shows the measurement results of complicated chairs with contradictory semantics. This chair (Table 10a) was made of many braided vines. Thus, the frequency distribution for the experts concentrated on the left (an average of 3.87), showing that they did a complex judgment for this chair. However, the frequency distribution for the novices focused on the center, showing that they believed that it involved a simple feature which supported by three-legged.

The chair (Table 10b) was made of metal lines and achieved 2D and 3D mixed views by using a visual illusion. The frequency distribution for the experts concentrated on the center (an average of 5.3). Because the experts would easily switch the different viewings based on their abilities of high imaginations and understand it performs a simple visual principle to create complex viewings. However, the frequency distribution for novices presented double peaks, showing that the some participants considered that this chair is conflict between complex and simple. There exists an opposite opinion for this chair between novices. 
Table 10. Complicated chairs with contradictory semantics.

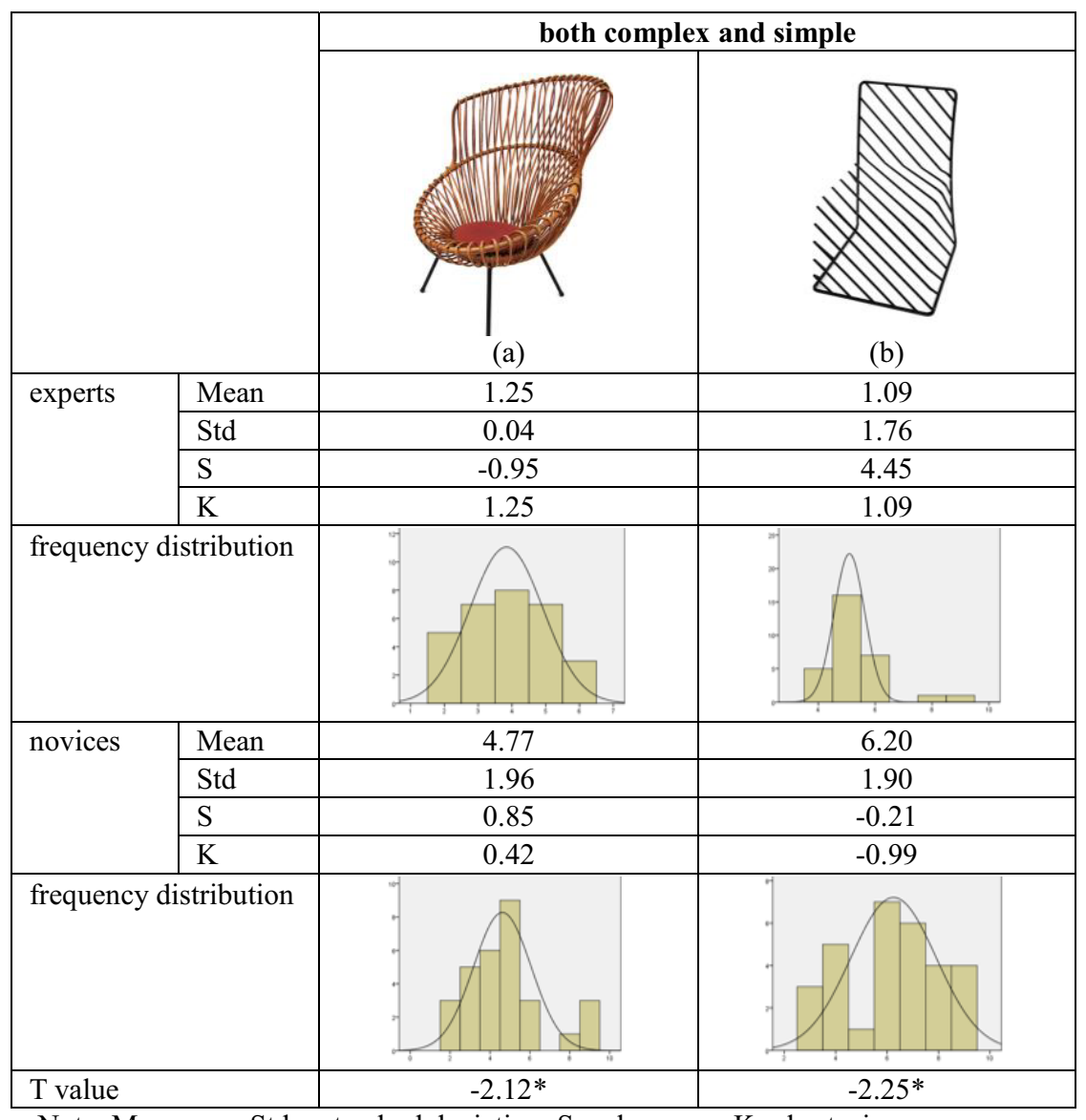

Note: $\mathrm{M}=$ mean; $\mathrm{Std}=$ standard deviation; $\mathrm{S}=$ skewness; $\mathrm{K}=$ kurtosis.

$* \mathrm{p}<.05$ and $* * \mathrm{p}<.01$ (2-tailed)

\section{Discussion}

In this study, we explore the product meaning with semantic contradictory and try to use the standard deviation to find the meanings of contradictory semantics. The results showed that the distributions of semantic differential ratings for the stimuli with contradictory meanings have higher standard deviations.

According to the [2], this suggested that the semantic contradiction would affect by three factors comprising at odds, contradiction, and insensitivity. We concluded that there are several reasons would impact the standard deviation. One explanation may be that the sensitivity of semantic recognition may depend on participant expertise. In general, the designers and artists could identify an artwork's category and style immediately according to their form, structure, material, and composition. Because the participants were not familiar with styling, experts might have been better able to detect the small feature differences. We considered that the experts with design training and background were much more sensitive to them. One the other hand, the novices had less knowledge and experience in distinguishing between objects using subtle visual cues. We considered that the mental mechanism of the imagination process would aggravate the expert's attention at the beginning, but diminish later because of less surprise relative to the others. Another possible reason may be that the artists and designers are trained to be good at visual thinking. To artists and designers, imagination is a key capability that is able to combine a new notion with existing one in novel ways to derive a new 
image [15]. The expected and unexpected outcomes of arrangements differentiate viewers' reinterpretation, and arouse the new connections of each component to generate a new impression [16].

This concept of combined different components into new image is similar to the tangram. Many educational researchers used the tangram to help student's development of spatial and geometric thinking by various compositions of triangles and portraying things with different angles [17-19]. The activity of assembling a graphic image of a tangram is similar to the endeavor of ready-made chairs (i.e. Table $4 \mathrm{~b}$ and Table $8 \mathrm{a}, \mathrm{b}, \mathrm{c}$ ) that is combined with various materials and turned into something useful. In this study, the experts who are used to design thinking could easily acquire the concept of ready-made chairs. On the contrary, ordinary people experienced difficulty in accepting them as a chair and revealed confusing reaction.

Overall, successful embedding of contradictory meanings into product forms are based on simple, typical, and rational forms that are made to simultaneously exhibit complex, novel, and emotional images by introducing additional elements. The "typical-unique" chairs are likely to have prototypical shapes with additional functions or embedded stories. The "traditional-modern" chairs are based on the traditional shape with additional modern materials. The "rational-emotional" chairs are combined with rigid rational and sensual cures. The "complicated-simple" chairs are achieved through the use of material, texture, and complicated product forms. Therefore, these design methods of operation should enable to arouse more inspirations to designers.

\section{Conclusion}

Meaning of practices and design theory in the result of this study, semantic dimension can be usually concerned positive meaning and opposite one. For example, the modern dimension "traditionalmodern". It still contained argues inside, just like design technique contrast which represented conflict semantic. Designer avoid create boring works, meanwhile, they understand contradictory semantics and help to expend the study domain of practice and theory. However, the studies of contradictory semantics are rare in this field. The measurement of using SD method is nearly subjective. It might be also hard to reveal the real feeling of participants. Therefore, it hopefully can be relative science of brain technology toward objective measurement. The further study will try to discovery the brain reactions and have more reasonable explanation the conflict semantic. It should be understood clearly for this topic.

\section{References}

1. C.E. Osgood, G.J. Suci, and P.H. Tannenbaum, The Measurement of Meaning, University of Illinois Press (Urbana, IL, 1957)

2. W.K. Hung and L.L. Chen, How to measure product's contradictory semantics, Journal of Design, 15 (4), 41-58 (2010)

3. M.H. Lin, C.Y. Wang, S.K. Cheng, and S.H. Cheng, An event-related potential study of semantic style-match judgments of artistic furniture, International Journal of Psychophysiology, 82, 188195 (2011)

4. M.H. Lin, Y.M. Fang, and C.Y. Wang, A preliminary study of applying ERP on users' reactions to web pages with different presentation formats, The Science of Design, 57 (5), 89-98 (2011b)

5. P.L. Gardner, Measuring ambivalence to science, Journal of Research in Science Teaching, 24 (3), 241-247 (1987)

6. S.J. Breckler, A comparison of numerical indexes for measuring attitude ambivalence, Educational and Psychological Measurement, 54, 350-365 (1994)

7. J.A. Russell, A circumplex model of affect, Journal of Personality and Social Psychology, 39 (6), 1161-1178 (1980)

8. R. Plutchik and H.R. Conte, Circumplex Models of Personality and Emotions, American Psychological Association (Washington D.C, 1996) 
9. R.E. Thayer, The Biopsychology of Mood and Activation (New York: Oxford University Press, 1989)

10. C.M. Whissell, Pleasure and activation revisited: Dimensions underlying semantic responses to fifty randomly selected "emotional" words, Perceptual and Motor Skills, 53, 871-874 (1981)

11. K.A. Hsiao and L.L. Chen, Fundamental dimensions of affective responses to product shapes, International Journal of Industrial Ergonomics, 36, 553-564 (2006)

12. P. Hekkert, D. Snelders, and P.C.W. Van Wieringen, Most advanced, yet acceptable: Typicality and novel as joint predictors of aesthetic preference in industrial design, British Journal of Psychology 94, 111-124 (2003)

13. C. Fiell and P. Fiell, 1000 Chairs (Kolin. Taschen, New York, USA, 1997)

14. R. Hemachandra, 500 Chairs: Celebrating Traditional and Innovative Designs (Lark Books, New York, USA, 2008)

15. J. Passmore, Recent Philosophers: A Supplement to a Hundred Years of Philosophy (Duckworth Publishing, New York, USA, 1985)

16. M. Suwa, T. Purcell, and J.S. Gero, Macroscopic analysis of design processes based on a scheme for coding designers' cognitive actions, Design Studies, 19, 455-483 (1998)

17. C.L. Chong and N.M. Siew, Fostering students' creativity through van hiele's 5 phase-based tangram activities, Journal of Education and Learning, 3 (2), 66-80 (2014)

18. C.P. Lin, Y.J. Shao, L.H. Wong, Y.J. Li, and J. Niramitranon, The impact of using synchronous collaborative virtual tangram in children's geometric, Turkish Online Journal of Educational Technology, 10 (2), 250-258 (2011)

19. N.M. Siew, C.L. Chong, and M.R. Abdullah, Facilitating students' geometric thinking through van hiele's phase-based learning using tangram, Journal of Social Sciences, 9 (3), 101-111 (2013) 